\title{
Health impacts of anthropogenic biomass burning in the developed world
}

\author{
Torben Sigsgaard ${ }^{1}$, Bertil Forsberg ${ }^{2}$, Isabella Annesi-Maesano ${ }^{3,4}$, \\ Anders Blomberg ${ }^{5}$, Anette Bølling ${ }^{6}$, Christoffer Boman ${ }^{7}$, Jakob Bønløkke ${ }^{1}$, \\ Michael Brauer ${ }^{8}$, Nigel Bruce ${ }^{9}$, Marie-Eve Héroux ${ }^{10}$, Maija-Riitta Hirvonen ${ }^{11}$, \\ Frank Kelly ${ }^{12}$, Nino Künzli ${ }^{13,14}$, Bo Lundbäck ${ }^{15}$, Hanns Moshammer ${ }^{16}$, \\ Curtis Noonan ${ }^{17}$, Joachim Pagels ${ }^{18}$, Gerd Sallsten ${ }^{19}$, Jean-Paul Sculier ${ }^{20}$ and \\ Bert Brunekreef ${ }^{21,22}$
}

\begin{abstract}
Affiliations: ${ }^{1}$ University of Aarhus, Institute of Public Health, Aarhus, Denmark. ${ }^{2}$ Dept of Public Health and Clinical Medicine/Environmental Medicine, Umeå University, Umeå, Sweden. ${ }^{3}$ INSERM UMR-S 1136, Institute Pierre Louis of Epidemiology and Public Health, Epidemiology of Allergic and Respiratory Diseases, Paris, France. ${ }^{4}$ UPMC, UMR-S 1136, Institute Pierre Louis of Epidemiology and Public Health, Epidemiology of Allergic and Respiratory Diseases, Paris, France. ${ }^{5}$ Dept of Public Health and Clinical Medicine/Medicine, Umeå University, Umeå, Sweden. ${ }^{6}$ Norwegian Institute of Public Health, Division of Environmental Medicine, Dept of Air Pollution and Noise, Oslo, Norway. ${ }^{7}$ Thermochemical Energy Conversion Laboratory, Dept of Applied Physics and Electronics, Umeå University, Umeå, Sweden. ${ }^{8}$ University of British Columbia, School of Population and Public Health, Vancouver, BC, Canada. ${ }^{9}$ WHO, Geneva, Switzerland. ${ }^{10}$ WHO Regional Office for Europe, Bonn, Germany. ${ }^{11}$ University of Eastern Finland, Kuopio, Finland. ${ }^{12}$ King's College London, London, UK. ${ }^{13}$ Swiss Tropical and Public Health Institute, Basel, Switzerland,. ${ }^{14}$ University of Basel, Basel, Switzerland. ${ }^{15}$ Krefting Research Centre, Institute of Medicine, University of Gothenburg, Gothenburg, Sweden. ${ }^{16}$ Medical University of Vienna, Institute of Environmental Health, Vienna, Austria. ${ }^{17}$ The University of Montana, Center for Environmental Health Sciences, Missoula, MT, USA. ${ }^{18}$ Lund University, Ergonomics and Aerosol Technology, Lund, Sweden. ${ }^{19}$ Division of Occupational and Environmental Medicine, Institute of Medicine, University of Gothenburg, Gothenburg, Sweden. ${ }^{20}$ University Jules Bordet, Brussels, Belgium. ${ }^{21}$ Utrecht University, Institute for Risk Assessment Sciences, Utrecht, The Netherlands. ${ }^{22}$ Julius Center for Health Sciences and Primary Care, University Medical Center Utrecht, Utrecht, The Netherlands.
\end{abstract}

Correspondence: Torben Sigsgaard, Aarhus University, Dept of Public Health, Section for Environment, Occupation and Health, Bartholin Allé 2 DK-8000 Aarhus C, Denmark. E-mail: tsaph.au.dk

ABSTRACT Climate change policies have stimulated a shift towards renewable energy sources such as biomass. The economic crisis of 2008 has also increased the practice of household biomass burning as it is often cheaper than using oil, gas or electricity for heating. As a result, household biomass combustion is becoming an important source of air pollutants in the European Union.

This position paper discusses the contribution of biomass combustion to pollution levels in Europe, and the emerging evidence on the adverse health effects of biomass combustion products.

Epidemiological studies in the developed world have documented associations between indoor and outdoor exposure to biomass combustion products and a range of adverse health effects. A conservative estimate of the current contribution of biomass smoke to premature mortality in Europe amounts to at least 40000 deaths per year.

We conclude that emissions from current biomass combustion products negatively affect respiratory and, possibly, cardiovascular health in Europe. Biomass combustion emissions, in contrast to emissions from most other sources of air pollution, are increasing. More needs to be done to further document the health effects of biomass combustion in Europe, and to reduce emissions of harmful biomass combustion products to protect public health.

@ERSpublications

Biomass combustion is an important source of air pollution and ill health in the EU: emissions need to reduce http://ow.ly/RYkPk 


\section{Introduction}

During the first half of the twentieth century, air pollution in many European cities was dominated by local emissions from fossil fuel combustion for space heating, energy production and manufacturing. As a consequence pollution episodes were common and often severe, like the smog episodes in London [1] and the Meuse valley [2] in Belgium, both associated with large and sudden increases in mortality. These and other episodes led the governments of different countries to introduce air pollution regulations, e.g. the Clean Air Act introduced in 1956 in the UK. Due to this change in practice and the increased availability of cleaner fuels such as oil and gas during the 1960s, air quality in many European cities improved markedly. Nevertheless, more recent studies have demonstrated continued adverse health effects of air pollution at much lower levels of exposure [3-5]. Recently it has also been shown that further decreases in air pollution had a beneficial effect on the life expectancy of the American population during the past few decades [6]. The World Health Organization (WHO), in its 2005 global update of the Air Quality Guidelines, set a guideline for fine particulate matter (PM) in air of just $10 \mu \mathrm{g} \cdot \mathrm{m}^{-3}$ as an annual average. This concentration is still exceeded in large parts of Europe, and continued efforts are needed to reduce fine particles from all sources.

Against this background, it is potentially worrying that, as a response to climate change policies and fuel pricing, biomass burning (primarily of wood) for residential space heating as well as energy production is now an increasing source of fine PM emissions in the European Union (EU), thus posing new challenges to human health. As a response to fuel poverty, in some communities, wood/biomass burning is seen as a cheap form of fuel when gathered locally. For example, a recent study in Greece documented a 30\% increase in winter PM, a 2.5-fold increase in biomass combustion markers and a $20-30 \%$ decrease in fuel oil tracers coinciding with the recent economic crisis [7].

A relatively small number of studies have evaluated the health effects of outdoor and indoor exposure to combustion products from fireplaces or wood stoves in developed countries [8-10]. However, extensive epidemiological literature exists that describes the adverse health effects of high-level exposure to pollution from household biomass combustion for cooking and heating purposes in developing countries [11-13]. This literature indicates causal links between PM and acute lower respiratory infections in young children, chronic obstructive pulmonary disease (COPD) in adults [14], and development of cataracts in women [15]. Lung cancer has also been linked to inhalation of biomass combustion products. Indoor emissions from biomass combustion and cooking in developing countries have been classified as probably carcinogenic (International Agency for Research on Cancer IARC Group 2A) [16].

Although combustion of biomass is known to produce numerous air pollutants, the focus of this report is PM emissions, which have received most of the attention in the scientific literature. Therefore, only epidemiological studies in which the primary measure for evaluation of biomass exposure is PM, or components thereof, are considered. This is consistent with the approach taken in prior reviews of biomass combustion health impacts [17, 18] and the Global Burden of Disease (GBD) 2010 report [19, 20]. This approach also follows the perspective of the WHO Air Quality guidelines [21], the review by NAEHER et al. [17] and the recent WHO REVIHAAP project report [22], which concluded that there was a lack of evidence supporting differential toxicity of PM from biomass combustion when compared with urban PM from fossil fuel combustion and secondary atmospheric particles.

This position paper deals with the effects of biomass smoke on respiratory and cardiovascular health in the developed world, where wood burning is primarily, but increasingly, used as an auxiliary source of domestic heating and energy production. When searching the literature, the following terms were used in a PubMed search: "wood smoke" OR "domestic heating" AND "USA OR Canada OR Europe OR Australia" AND "wood stove" AND "health". In addition to the search we consulted international experts and research centres active in the field.

\section{Biomass combustion emissions in developed countries}

Estimates from several countries have shown that biomass (primarily wood) burning is contributing substantially to the total concentrations of PM in the local environment. Studies from Denmark and Sweden have found air pollution concentrations from wood burning in rural areas with limited traffic to be

This article has supplementary material available from erj.ersjournals.com

Received: Oct 082014 | Accepted after revision: Sept 012015 | First published online: Sept 242015

The authors alone are responsible for the views expressed in this publication and they do not necessarily represent the decision or stated policy of the World Health Organization.

Conflict of interest: Disclosures can be found alongside the online version of this article at erj.ersjournals.com 
in the same range as those from traffic in major cities $[23,24]$. Estimates of the current situation for some European countries (i.e. Sweden, Finland, Germany and Austria) indicate 15-25\% of particles with a 50\% cut-off aerodynamic diameter of $<2.5 \mu \mathrm{m}$ (PM2.5) originate from residential biomass combustion [25] and data from Alpine valleys indicate contributions of 50\% or more. From a European perspective, it has been estimated that small scale domestic wood/biomass combustion will become the dominant source of fine primary particle air pollution by 2020 [26], with a contribution of $38 \%$ of total emissions (figs 1 and 2). More recently the International Institute for Applied Systems Analysis estimated that, between 2005 and 2030, the use of biomass for energy production in the EU will double, whereas use of coal, gas and oil are all expected to decrease [27]. Another study estimated that of all external health costs occurring in Denmark as a result of Danish air pollution emissions, woodsmoke generated by domestic heating was responsible for $16 \%$ of these costs in 2000 , and subsequently reached $30 \%$ in 2008 due to an $80 \%$ increase in the use of wood for domestic heating in Denmark over that period [28].

Within the EU, biomass is used in small scale residential ( $<50$ kilowatt thermal $(\mathrm{kWth}))$ heating appliances and in medium scale ( $<20 \mathrm{MWth}$ ) district heating/industrial systems as well as in large centralised heat and power plants. In the small and medium scale sector, a large number of units are in use and the technology covers a vast range, from the simplest fireplaces to fully automated systems. The current number of residential biomass combustion systems within the $\mathrm{EU}$ is estimated to be $\sim 65$ million direct heating appliances (fireplaces, stoves and cookers) and $\sim 8$ million indirect heating appliances (boilers), firing mainly using wood logs but also wood chips and fuel pellets [24]. The technological level has traditionally been low, as has the combustion efficiency and emission performance. It is generally understood, although poorly documented, that behavioural factors can have a large impact on residential stove emissions, including wood sizing, fuel moisture content, ignition procedure, burn temperatures and stove maintenance [29, 30]. Recent developments have resulted in modern appliances with decreased emissions, but still, these systems are often sensitive to firing procedures and are not optimised in real life-operation. Moreover, emissions during the starting phase remain magnitudes higher than in the stationary phase even in modern appliances [31, 32]. Thus, significant potential for further emission reduction remains [25].

The typical PM2.5 emission factors given range from 40-300 and 50-2000 mg. $\mathrm{MJ}^{-1}$ for modern and conventional domestic wood stoves, respectively [33]. When using humid fuels and poorly insulated stoves, the PM2.5 emissions may be significantly elevated (grammes per MJ). Emissions from such low-temperature combustion are often completely dominated by liquid droplets consisting of a complex array of organic components [34]. Combustion may also be too intense when using very dry fuel in well insulated stoves, thus resulting in so-called "air-starved" conditions. Such combustion may contain the highest emissions of carcinogenic polycyclic aromatic hydrocarbons (PAHs) and is dominated by solid agglomerated soot (black carbon) particles, which shows similarities to diesel soot $[32,35]$.

Modern biomass combustion technologies such as automatic small-scale wood pellet appliances and larger domestic heating plants are commonly more efficient and have much lower particle emissions in the range of $10-50 \mathrm{mg} \cdot \mathrm{MJ}^{-1}$ (typically $<30 \mathrm{mg} \cdot \mathrm{MJ}^{-1}$ ) [33]. Using these technologies, organic and soot emissions may

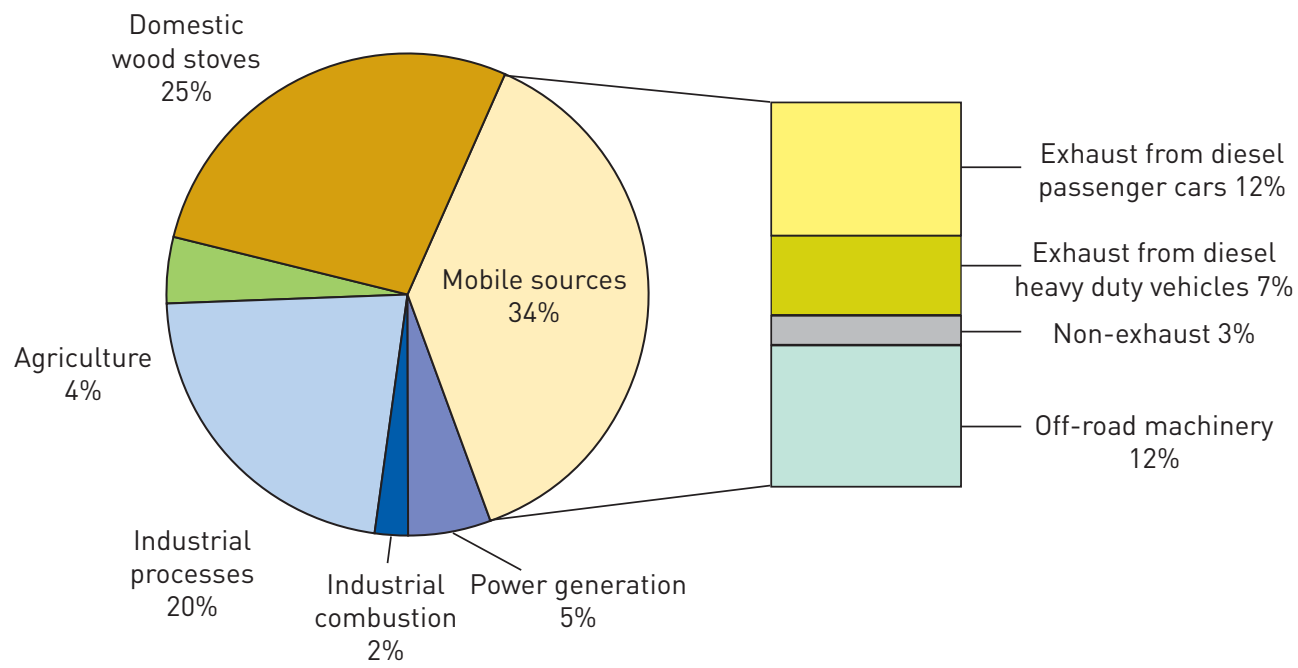

FIGURE 1 Sector contributions to primary particles with a $50 \%$ cut-off aerodynamic diameter of $<2.5 \mu$ m emissions in the EU15, 2000. Reproduced from [26]. 


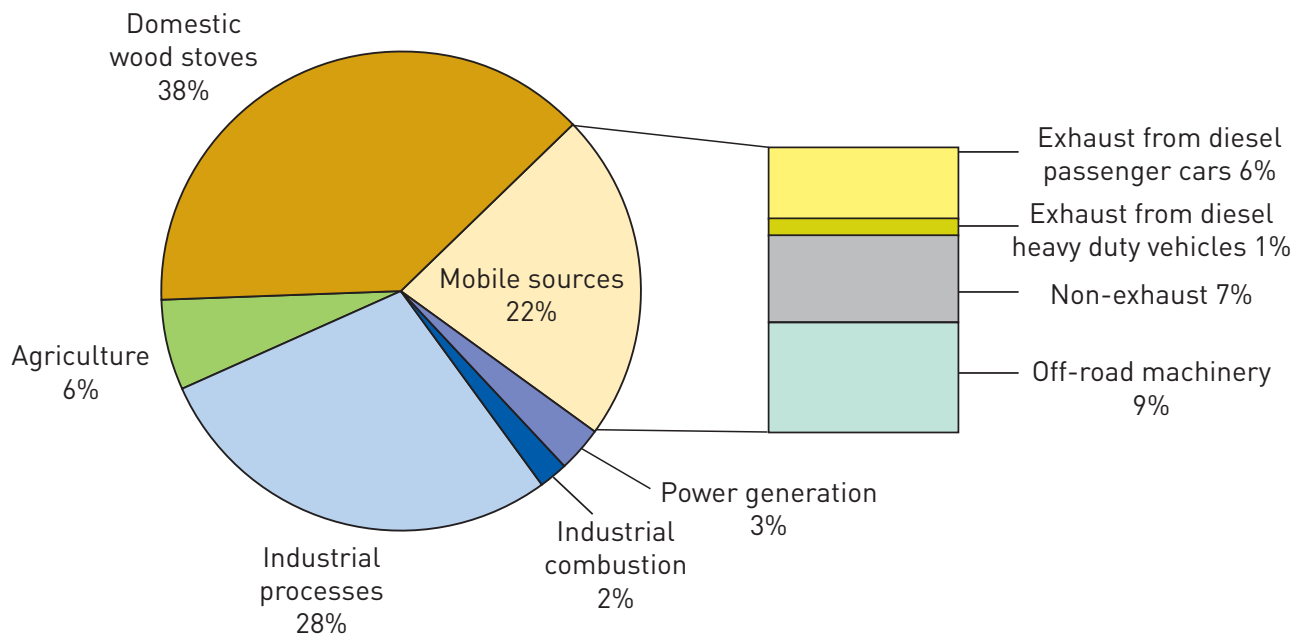

FIGURE 2 Sector contributions to primary particles with a $50 \%$ cut-off aerodynamic diameter of $<2.5 \mu \mathrm{m}$ emissions in the EU15, 2020. Reproduced from [26].

be almost completely eliminated, and the particle emissions are instead dominated by inorganic salts like potassium sulfates and chlorides, with minor amounts of zinc.

Further information on biomass combustion technology is provided in the online supplementary material.

\section{Exposure}

The contribution of woodsmoke to ambient PM mass is highly dependent on season, density of sources and the specific technologies employed as well as meteorology and topography. Studies have estimated that wood/biomass combustion contributes $10-30 \%$ or $\sim 1-4 \mu \mathrm{g} \cdot \mathrm{m}^{-3}$ to the annual average fine particle concentrations measured in different parts of Europe. Details of the studies and methods applied can be found in the online supplemental material. Tables S1-S3 show the contributions of biomass combustion to outdoor and indoor PM concentrations in the developed world. In some cases wood combustion is the major source of ambient PM, especially during the heating season. Woodsmoke also contributes substantially to some of the particle components that are considered particularly harmful such as particle-bound PAH, volatile organic compounds and metals [23, 36-40].

While air pollution from woodsmoke is often highest in close vicinity to houses where and when wood burning takes place [40], there is also a more global contribution of biomass combustion from indoor heating and cooking, energy production, and from agricultural and wild fires even at distant background stations [41] and over the oceans [42]. Outdoor woodsmoke concentrations may be less predictive for individual exposure compared with other air pollutants because of the potential for wood stoves to emit pollution indoors, and wood combustion for heating occurs in locations and during periods when indoor infiltration may be relatively low due to building construction (insulation) and operation (closed windows) $[43,44]$. Therefore, unsurprisingly, studies evaluating fine particle levels in homes with wood-burning appliances have given mixed results, ranging from indoor particles with a $50 \%$ cut-off aerodynamic diameter of $<10 \mu \mathrm{m}$ (PM10) levels as high as $100 \mu \mathrm{g} \cdot \mathrm{m}^{-3}[45,46]$ to only minor differences between indoor concentrations measured in homes with and without wood burning appliances. In a few studies looking at woodsmoke tracers, significant differences (66-80\%) were observed for potassium, calcium and zinc as well as 1,3-butadiene and benzene $[47,48]$. In one study, the levels of benzo(a)pyrene and several other PAHs were found to be three- to five-fold higher in homes with wood combustion appliances compared with homes without [49].

\section{Epidemiology}

Health effects of anthropogenic biomass combustion products in the developed world

Whereas there is a vast literature on health effects of indoor air pollution from biomass burning in the developing world [11], comparatively few studies have addressed health effects of biomass burning in the developed world. We will first discuss epidemiological observations from areas where biomass combustion (mostly wood burning) is a relatively important source of ambient air pollution. We will then discuss smaller-scale studies of populations living in homes using wood for heating and/or cooking.

Several studies have looked at the health effects of air pollution in Seattle, USA and Vancouver, Canada where, in winter, residential wood burning is an important contributor to outdoor PM pollution. A time 
series study conducted in Seattle documented that in the cold season, ambient PM2.5 was associated with total and cardiovascular (but not respiratory) mortality [50]. Interestingly, potassium, a marker of woodsmoke, also showed positive associations with total and cardiovascular mortality in the cold season. A study from Vancouver also showed positive associations between PM10 in winter and total mortality [51].

Other studies from Seattle found associations between PM and respiratory symptoms (chest congestion and wheeze) in young children [52], increased medication use [53], decreased lung function [54], emergency room visits for asthma [55] and hospitalisations [56]. Smaller studies on cardiovascular morbidity end-points generally found little evidence for effects on sudden cardiac arrest [57], myocardial infarction [58], heart rate variability [59], and measures of systemic inflammation or thrombosis [60].

There are few epidemiological studies of chronic or sub-chronic exposure to biomass PM resulting from residential wood burning as a heat source. In metropolitan Vancouver, extensive mobile monitoring and geospatial modelling were used to develop a spatio-temporal model of ambient winter woodsmoke [61], which was applied to a variety of health outcomes. Positive associations were reported with low birth weight [62], infant bronchiolitis [63], otitis media [64] and COPD hospitalisation. However, no association was found for COPD mortality [65] or for incident childhood asthma [66].

A study conducted in southern California reported significant positive associations between the biomass combustion source fraction and preterm birth [67], although not with term low birth weight [68], which was also not associated with PM mass.

In Europe, some studies have estimated the acute exposure impacts of particle source apportionment in locations where biomass combustion is a more minor contributor to ambient PM. For example, in a study conducted in Copenhagen, associations were reported between the biomass source fraction and respiratory and cardiovascular hospital admissions in the elderly (age $>65$ years), but not for asthma-related admissions among children [69]. Of these, only the associations with respiratory admissions remained significant after adjustment for the contributions from other sources.

In Christchurch, New Zealand, source apportionment studies indicated that $90 \%$ of wintertime PM originated from wood combustion, and ambient PM10 was associated with increased respiratory and cardiovascular (excluding ischaemic heart disease) hospital admissions [70]. In a study conducted in Temuco, Chile, where an estimated $87 \%$ of winter PM10 was attributable to wood combustion, PM10 was associated with cardiovascular and respiratory mortality, hospitalisations, and emergency room visits for acute respiratory infections [71]. This study was conducted in an area where the average PM10 concentration was $46 \mu \mathrm{g} \cdot \mathrm{m}^{-3}$ with daily means often well above $150 \mu \mathrm{g} \cdot \mathrm{m}^{-3}$, i.e. much higher than concentrations measured in Seattle, USA and Vancouver, Canada.

\section{Health impacts of community and household stove interventions}

Studies of community- or household-level health impacts following wood stove intervention strategies have been limited. Table 1 highlights results on effects of interventions such as wood stove change out programmes on ambient PM levels in the developed world; table S2 shows the effects on indoor PM

TABLE 1 Effects of wood stove interventions on outdoor particulate matter (PM) levels in developed countries

\begin{tabular}{|c|c|c|c|}
\hline Location & $\begin{array}{l}\text { Estimated reduction } \\
\text { in } \mathrm{PM} \mu \mathrm{g} \cdot \mathrm{m}^{-3}\end{array}$ & Notes & References \\
\hline Launceston, Tasmania, Australia & $\begin{array}{l}38 \% \text { reduction in } \\
\text { winter } \mathrm{PM}_{10}\end{array}$ & $\begin{array}{c}\text { Fuel switching: replacement of wood heating appliances with } \\
\text { electric heating appliances. The proportion of households } \\
\text { burning wood was reduced from } 66 \% \text { to } 30 \% \text {. }\end{array}$ & {$[72]$} \\
\hline British Colombia, Canada & $\begin{array}{l}22 \% \text { reduction in } \\
\text { winter } \mathrm{PM} 2.5\end{array}$ & $\begin{array}{l}\text { Introduction of improved technology stoves and targeting of open } \\
\text { fireplaces. The proportion of homes using open fireplaces was } \\
\text { reduced from } 15 \% \text { to } 3 \% \text {, and the proportion of homes with } \\
\text { improved technology wood stoves increased from } 25 \% \text { to } 41 \% \text {. } \\
\text { The community also had an overall increase in wood stove usage. }\end{array}$ & [73] \\
\hline Missoula, MT, USA & $\begin{array}{l}45 \% \text { reduction in } \\
\text { PM10 }\end{array}$ & $\begin{array}{c}\text { Legislative action and enforcement. Over a } 10 \text {-year period, } \\
\text { the proportion of households burning wood was reduced } \\
\text { from } 44 \% \text { to } 20 \% \text { and the contribution of residential wood } \\
\text { burning to } \mathrm{PM} 10 \text { was reduced from } 47 \% \text { to } 11 \% \text {. }\end{array}$ & {$[74]$} \\
\hline Libby, MT, USA & $\begin{array}{l}27 \% \text { reduction in } \\
\text { winter } \mathrm{PM} 2.5\end{array}$ & $\begin{array}{l}\text { Introduction of improved technology stoves. Over } 1100 \text { older model } \\
\text { wood stoves were replaced with improved technology stoves. }\end{array}$ & {$[75,76]$} \\
\hline
\end{tabular}

PM10: particles with a 50\% cut-off aerodynamic diameter of $<10 \mu \mathrm{m}$; PM2.5: particles with a $50 \%$ cut-off aerodynamic diameter of $<2.5 \mu \mathrm{m}$. 
concentrations. A 4-year, survey-based study tracked parent-reported respiratory symptoms and conditions among school children during the community wood stove exchange in Libby, Montana, USA. Significant reductions in reported frequency per $5 \mu \mathrm{g} \cdot \mathrm{m}^{-3}$ decline in ambient PM2.5 were observed for wheeze (27\%), irritant symptoms such as watery eyes (33\%), cold (25\%), bronchitis (55\%), flu (52\%) and throat infection (45\%) [75]. No significant reductions were observed for reported ear infection, but the population studied was not in the age group most commonly impacted by this condition. In the same community, no consistent effects were observed for school absences.

In Launceston, Tasmania, Australia, substantial mortality changes were observed between the period before (1994-2000) and after (2001-2007) a government-coordinated fuel switching effort. The investigators demonstrated significant reductions in male mortality only: $18 \%$ from cardiovascular causes and $28 \%$ from respiratory causes [72]. Similar findings of borderline significance were observed for winter mortality for both sexes combined.

Finally, a high-efficiency particulate air filter intervention crossover study examined changes in microvascular endothelial function as measured by reactive hyperaemia index (RHI) as well as changes in serum and urine markers of oxidative stress and inflammation [77]. In this study, filtration units were placed in homes with and without wood stoves to reduce indoor PM concentrations. The use of the filter was associated with significantly higher mean measures of RHI (9\%) and significantly lower mean measures of the inflammatory marker C-reactive protein (CRP) (33\%). These findings remained robust when the analyses were restricted to participants in wood stove homes, but not among participants in non-wood stove homes. Smaller magnitude and nonsignificant changes in RHI and CRP were found when modelled per $\mu \mathrm{g} \cdot \mathrm{m}^{-3}$ reduction in indoor PM2.5 rather than per filter on/off status, possibly reflecting between-home variability in smoke infiltration. A recent study conducted in an urban area at very low levels of ambient and indoor PM2.5 was, however, not able to reproduce these findings [78].

\section{Wild fires}

The respiratory health effects associated with wildfire smoke exposure have recently been reviewed in detail $[79,80]$, and are summarised here to provide supporting evidence of the health impacts resulting from exposure to biomass combustion products. Similar to the literature described above for domestic biomass combustion, wildfire smoke exposure was associated with respiratory symptoms, increased asthma medication use, outpatient physician visits, emergency room visits, hospital admissions and mortality. Stronger associations were observed for asthma-specific physician visits, hospitalisations and emergency room visits, as well as for respiratory symptoms among individuals with asthma compared with non-asthmatic individuals. Relatively few studies have reported on the relationship between cardiovascular outcomes and wildfire smoke, with varying specificity in exposure estimates. A number have reported null associations for mortality [81], hospital admissions [82] and outpatient physician visits [83], despite evidence of positive associations for measures of respiratory health. However, several recent studies have reported associations between forest fire smoke exposure and cardiac outcomes including emergency visits for heart failure [83], out of hospital cardiac arrest [84-86] and cardiac mortality [87, 88].

\section{Toxicity of woodsmoke particles}

The physicochemical properties of biomass combustion PM varies between different combustion conditions. As discussed in the online supplementary material, the heterogeneity of biomass PM characteristics is high. Accordingly, evaluation of the respiratory and cardiovascular toxicity of biomass emission PM is complex. The limited knowledge of physicochemical properties of ambient (real-life) biomass PM exposure further complicates the evaluation of the possible health risks associated with biomass PM exposure.

\section{Impact of combustion conditions and particle properties}

Woodsmoke particles constitute a complex and variable mixture of organic-dominated particles, soot agglomerates and inorganic ash alkali particles; three particle types that differ considerably in shape, size, solubility and chemical composition [89]. Health relevant properties of these particle types are described in more detail in the online supplementary material. These differences in physicochemical properties may affect various aspects of PM-induced toxicity, including pulmonary deposition, clearance and cellular effects. For instance, soluble inorganic ash particles are cleared rapidly from the lungs compared with insoluble soot agglomerates. The pulmonary deposition is determined by size, shape and hygroscopicity. For biomass PM, hygroscopic particle growth in the respiratory tract has a large impact on particle deposition probability [90-92]. Biomass PM from complete and incomplete combustion exhibited relatively low deposited fractions in the respiratory tract, while ambient woodsmoke PM (likely originating from mixed combustion conditions) resulted in larger deposited fractions. Although the ambient woodsmoke deposition was lower than for vehicular traffic particles (38\% versus $69 \%$ for particle number concentrations), the alveolar deposited fractions were estimated to be $\sim 20 \%$ for both types of particles [92]. Differences in pulmonary 
deposition for different types of biomass PM possibly affect the severity of the respiratory and cardiovascular effects, but this has not been specifically addressed in human inhalation studies. In cell culture studies, the chemical composition and combustion conditions have a large impact on the cellular effects induced by biomass PM. Various organic compounds influence the biological effects of PM resulting from poor combustion, whereas metals are of major importance for the effects induced by inorganic ash particles from complete combustion [89, 93-95]. These findings have also been confirmed in vivo in two short-term instillation studies of different types of biomass PM [94, 95]. It is important to keep in mind that these in vitro and in vivo studies do not account for differences in pulmonary particle deposition and clearance, which are also influenced by the combustion conditions and the resulting PM properties. Physicochemical ageing in the atmosphere, by reaction of the emissions with hydroxyl radicals and ozone, chemically transforms the primary biomass PM. For example PAHs may be transformed to quinones and nitro-PAHs [96]. This also leads to formation of low volatility vapours that add new secondary organic particle mass (on the timescale of minutes to days). Currently, it is not known if atmospheric ageing leads to increased or decreased toxicity. An initial study showed effects of ageing by ozone on biomass PM characteristics and toxicity [97].

\section{Toxicological effects related to human health}

Human controlled exposure studies report that short-term inhalation of woodsmoke induces mild inflammatory effects including distal airway inflammation, increased oxidative stress and immune cell recruitment, but no effects on measures of lung function [98-103]. Studies also report systemic effects such as increased levels of coagulation markers, and decreased heart rate variability and systemic inflammation [100, 104-107]. In mice and rats, long-term inhalation of woodsmoke in concentrations relevant for ambient exposure induces mild inflammatory effects in the airways, systemic inflammation and decreased lung function [17, 108-112]. Woodsmoke PM has also been reported to exacerbate allergic inflammation and allergic sensitisation, and to decrease pulmonary macrophage function in terms of impaired infection resistance $[17,109,112-114]$, this was recently demonstrated to apply equally to particles from Malawian and Norwegian woodsmoke [115]. Overall, in vivo and in vitro experiments demonstrate that woodsmoke PM can induce inflammatory responses, cytotoxicity, genotoxicity, oxidative stress and immunosuppressive effects $[17,93-95,104,111,116-122]$. Atopy alone did not appear to increase susceptibility to the toxic effects of woodsmoke PM [123], whereas conditions affecting deposition, such as pre-existing lung disease, have yet to be studied in biomass combustion product experiments.

While some human inhalation studies report significant respiratory and systemic effects, other studies have not found these. This ambiguity could partly be due to the great heterogeneity in experimental set-ups, fuel type, biomass exposure generation and physicochemical properties of PM. Interestingly, the two studies reporting significant effects for either respiratory or cardiovascular end-points applied biomass PM originating from flaming combustion of wood logs in conventional stoves, rendering emissions of soot and organics [98, 99, 104, 105]. Other studies applied PM from more complete or more incomplete (smouldering) combustion conditions. This may point towards an influence of combustion conditions and physicochemical properties on the effects reported in the human exposure studies.

The high variability in respiratory and cardiovascular effects reported in the human inhalation studies could be due, in part, to differences in the physicochemical properties of the applied biomass PM. This reflects the inherent complexities in the evaluation of health risks from a very heterogeneous class of PM. The mild inflammatory effects following short-term, controlled inhalation of woodsmoke in healthy individuals are in accordance with the mild inflammatory effects reported in animal models. However, these data cannot be extrapolated to long-term exposure scenarios or effects in susceptible individuals. Also, based on the current, limited experimental findings, we cannot conclude that exposure to residential biomass emissions in developed countries is less harmful than exposure to combustion particles from fossil fuel combustion.

\section{Policy implications}

Air pollution arising from wood burning has been recognised as a problem for some time in Scandinavian and Alpine countries, especially during the winter period. Across Europe, the Renewable Energy Directive has set a goal to produce $20 \%$ of energy from renewable sources by 2020 , increasing wood/biomass combustion for power generation. As mentioned in the Introduction, biomass combustion is expected to become the major source of primary PM emissions over the next 5-15 years. This will compromise efforts to reduce ambient PM concentrations to below the current WHO Air Quality Guidelines. This, in turn, will probably result in large numbers of avoidable, premature deaths across Europe over that time period.

Between 2010 and 2020, biomass burning is forecast to increase by $57-110 \%$ across the EU [124]. The UK alone is stimulating through financial incentives 700000 homes to convert to biomass heating systems, and biomass boilers are increasingly installed to meet renewable energy requirements. 
So far, the emission limits that exist within the EU and the rest of the developed world for new small-scale biomass combustion devices are rather tolerant and easily fulfilled by today's systems. The measuring methods applied and emission limits still vary, thus the need for harmonisation is obvious. To date, insufficient efforts have been made towards the development of particulate emission control devices for these units. The situation is, however, currently under revision, and considerably tougher and harmonised emission standards are under discussion within the EU (e.g. related to the EcoDesign directive). In parallel with new technological solutions, it is also important to educate wood stove owners in the best wood burning practices based on recent research. Still, a considerable pollution contribution from existing residential installations will most probably continue.

Furthermore, it is expected that smaller, decentralised biomass installations will become more important in future energy supply scenarios. To enable an increased bioenergy sector, unexploited raw materials other than those based on stem wood (e.g. from forestry, agricultural sector and industrial residues) will have to be utilised. Compared with traditional wood fuels, these fuels have a higher content of fine particle forming ash matter and trace metals [125].

As outlined earlier in this review, there is increasing evidence of adverse health effects of wood/biomass combustion emissions as currently dominated by those from small inefficient stoves, which places this renewable energy source in direct conflict with its perception as a healthy source of energy and domestic heating. The potential for adverse health effects associated with biomass emissions also conflicts with their role in reducing other exposures forcing climate change. A conservative estimate of the current contribution of biomass smoke to premature mortality in Europe would amount to at least 40000 deaths per year. This is based on a contribution of biomass smoke to population exposure of $10 \%$, and recent estimates of the total mortality burden due to PM exposure in Europe (EU28) of over 400000 premature deaths each year [126]. A recent WHO report estimated that ambient PM from residential heating with wood and coal is responsible for 61000 premature deaths per year in the EU28 [127]. This latter estimate is dominated by woodsmoke.

Modern and more efficient biomass technologies are available, and further development and implementation of such systems are clearly motivated from an air pollution mitigation perspective. In addition, an important regulatory step would be the unconditional adoption of the PM10 and PM2.5 WHO annual mean Air Quality Guideline values to protect public health [128]. Compliance with these science-based guideline values (annual mean PM10 and PM2.5 concentrations of 20 and $10 \mu \mathrm{g} \cdot \mathrm{m}^{-3}$, respectively) would inevitably require the development and implementation of clean air strategies and "best available technology" for biomass combustion, comparable to the EU control policies for vehicle emissions.

\section{Conclusions}

Biomass combustion is widespread, is increasing, and makes an important contribution to ambient PM2.5, especially in winter, in the developed world.

Epidemiological studies strongly suggest that there are adverse health effects related to short-term as well as long-term exposure to biomass smoke in the developed world. Intervention studies performed, to date, suggest beneficial health effects of reducing exposure to biomass smoke. We recommend that emissions from biomass combustion should be kept to a minimum to protect public health.

As the evidence from studies in the developed world is still limited, further studies are necessary to more precisely quantify the adverse health effects of biomass combustion. This should include comparative studies to document similarities and differences between effects of combustion products from biomass and fossil fuels.

\section{Acknowledgements}

This position paper is the result of a workshop convened and supported by the European Respiratory Society in Brussels, Belgium, March 6-7, 2014. We sincerely thank the constructive assessment and many suggestions received from the European Respiratory Journal peer reviewers, which significantly increased the quality and scope of our original submission.

\section{References}

Logan WP. Mortality in the London fog incident, 1952. Lancet 1953; 1: 336-338.

Nemery B, Hoet PH, Nemmar A. The Meuse Valley fog of 1930: an air pollution disaster. Lancet 2001; 357: 704-708.

3 Pope CA 3rd, Burnett RT, Thun MJ, et al. Lung cancer, cardiopulmonary mortality, and long-term exposure to fine particulate air pollution. JAMA 2002; 287: 1132-1141.

4 Beelen R, Raaschou-Nielsen O, Stafoggia M, et al. Effects of long-term exposure to air pollution on natural-cause mortality: an analysis of 22 European cohorts within the multicentre ESCAPE project. Lancet 2014; 383: 785-795.

5 Crouse DL, Peters PA, van Donkelaar A, et al. Risk of nonaccidental and cardiovascular mortality in relation to long-term exposure to low concentrations of fine particulate matter: a Canadian national-level cohort study. Environ Health Perspect 2012; 120: 708-714. 
Correia AW, Pope CA 3rd, Dockery DW, et al. Effect of air pollution control on life expectancy in the United States: an analysis of 545 U.S. counties for the period from 2000 to 2007. Epidemiology 2013; 24: 23-31.

7 Saffari A, Daher N, Samara C, et al. Increased biomass burning due to the economic crisis in Greece and its adverse impact on wintertime air quality in Thessaloniki. Environ Sci Technol 2013; 47: 13313-13320.

Triche EW, Belanger $\mathrm{K}$, Bracken $\mathrm{MB}$, et al. Indoor heating sources and respiratory symptoms in nonsmoking women. Epidemiology 2005; 16: 377-384.

9 Van Miert E, Sardella A, Nickmilder M, et al. Respiratory effects associated with wood fuel use: a cross-sectional biomarker study among adolescents. Pediatr Pulmonol 2012; 47: 358-366.

10 Robin LF, Less PS, Winget M, et al. Wood-burning stoves and lower respiratory illnesses in Navajo children. Pediatr Infect Dis J 1996; 15: 859-865.

11 Mortimer K, Gordon SB, Jindal SK, et al. Household air pollution is a major avoidable risk factor for cardiorespiratory disease. Chest 2012; 142: 1308-1315.

12 Po JY, FitzGerald JM, Carlsten C. Respiratory disease associated with solid biomass fuel exposure in rural women and children: systematic review and meta-analysis. Thorax 2011; 66: 232-239.

13 Smith KR, Bruce N, Balakrishnan K, et al. Millions dead: how do we know and what does it mean? Methods used in the comparative risk assessment of household air pollution. Annu Rev Public Health 2014; 35: $185-206$.

14 Salvi SS, Barnes PJ. Chronic obstructive pulmonary disease in non-smokers. Lancet 2009; 374: 733-743.

15 Pokhrel AK, Smith KR, Khalakdina A, et al. Case-control study of indoor cooking smoke exposure and cataract in Nepal and India. Int J Epidemiol 2005; 34: 702-708.

16 International Agency for Research on Cancer. Household Use of Solid Fuels and High-Temperature Frying (IARC Monographs on the Evaluation of Carcinogenic Risks to Humans). Lyon, International Agency for Research on Cancer, 2010.

17 Naeher LP, Brauer M, Lipsett M, et al. Woodsmoke health effects: a review. Inhal Toxicol 2007; 19 : 67-106.

18 Boman BC, Forsberg AB, Jarvholm BG. Adverse health effects from ambient air pollution in relation to residential wood combustion in modern society. Scand J Work Environ Health 2003; 29: 251-260.

19 Lim SS, Vos T, Flaxman AD, et al. A comparative risk assessment of burden of disease and injury attributable to 67 risk factors and risk factor clusters in 21 regions, 1990-2010: a systematic analysis for the Global Burden of Disease Study 2010. Lancet 2012; 380: 2224-2260.

20 Brauer M, Amann M, Burnett RT, et al. Exposure assessment for estimation of the global burden of disease attributable to outdoor air pollution. Environ Sci Technol 2012; 46: 652-660.

21 WHO. WHO Air Quality Guidelines. Global Update 2005, Copenhagen, WHO Regional Office for Europe, 2006.

22 WHO. Review of evidence on health aspects of air pollution - REVIHAAP project technical report. Copenhagen, WHO Regional Office for Europe, 2013.

23 Glasius M, Ketzel M, Wahlin P, et al. Impact of wood combustion on particle levels in a residential area in Denmark. Atmos Environ 2006; 40: 7115-7124.

24 Krecl P, Larsson EH, Strom J, et al. Contribution of residential wood combustion and other sources to hourly winter aerosol in Northern Sweden determined by positive matrix factorization. Atmos Chem Phys 2008; 8: 3639-3653.

Jokiniemi J, Hytönen K, Tissari J. Biomass combustion in residential heating: Particulate measurements, sampling, and physicochemical and toxicological characterisation. Final report of the project BiomassPM within the ERA-NET Bioenergy Programme. Kuopio, University of Kuopio, 2008.

26 Amann M, Bertok I, Cofala J, et al. Baseline Scenarios for the Clean Air for Europe (CAFE) Programme. Laxenburg, International Institute for Applied Systems Analysis, 2005.

27 Amann M. The Final Policy Scenarios of the EU Clean Air Policy Package. Laxenburg, International Institute for Applied Systems Analysis, 2014.

28 Brandt J, Silver JD, Christensen JH, et al. Contribution from the ten major emission sectors in Europe and Denmark to the health-cost externalities of air pollution using the EVA model system - an integrated modelling approach. Atmos Chem Phys 2013; 13: 7725-7746.

29 Petersen LK. Autonomy and proximity in household heating practices: the case of wood-burning stoves. J Environ Policy Plann 2008; 10: 423-438.

30 Johansson LS, Leckner B, Gustavsson L, et al. Emission characteristics of modern and old-type residential boilers fired with wood logs and wood pellets. Atmos Environ 2004; 38: 4183-4195.

31 Heringa MF, DeCarlo PF, Chirico R, et al. Time-resolved characterization of primary emissions from residential wood combustion appliances. Environ Sci Technol 2012; 46: 11418-11425.

32 Eriksson AC, Nordin EZ, Nystrom R, et al. Particulate PAH emissions from residential biomass combustion: time-resolved analysis with aerosol mass spectrometry. Environ Sci Technol 2014; 48: 7143-7150.

33 Bolling AK, Pagels J, Yttri KE, et al. Health effects of residential wood smoke particles: the importance of combustion conditions and physicochemical particle properties. Part Fibre Toxicol 2009; 6: 29.

34 Orasche J, Schnelle-Kreis J, Schon C, et al. Comparison of emissions from wood combustion. Part 2: impact of combustion conditions on emission factors and characteristics of particle-bound organic species and polycyclic aromatic hydrocarbon (PAH)-related toxicological potential. Energy Fuels 2013; 27: 1482-1491.

35 Pettersson E, Boman C, Westerholm R, et al. Stove performance and emission characteristics in residential wood log and pellet combustion, part 2: wood stove. Energy Fuels 2011; 25: 315-323.

36 Molnàr P, Sallsten G. Contribution to PM2.5 from domestic wood burning in a small community in Sweden. Environ Sci Process Impacts 2013; 15: 833-838.

37 Glasius M, Ketzel M, Wåhlin P, et al. Characterization of particles from residential wood combustion and modelling of spatial variation in a low-strength emission area. Atmos Environ 2008; 42: 8686-8697.

38 Mandalakis M, Gustafsson O, Alsberg T, et al. Contribution of biomass burning to atmospheric polycyclic aromatic hydrocarbons at three European background sites. Environ Sci Technol 2005; 39: 2976-2982.

39 Gaeggeler K, Prevot ASH, Dommen J, et al. Residential wood burning in an Alpine valley as a source for oxygenated volatile organic compounds, hydrocarbons and organic acids. Atmos Environ 2008; 42: 8278-8287.

40 Hellen H, Hakola H, Haaparanta S, et al. Influence of residential wood combustion on local air quality. Sci Total Environ 2008; 393: 283-290.

41 Puxbaum H, Caseiro A, Sánchez-Ochoa A, et al. Levoglucosan levels at background sites in Europe for assessing the impact of biomass combustion on the European aerosol background. J Geophys Res 2007; 112: 16. 
$\mathrm{Hu} \mathrm{QH}$, Xie ZQ, Wang XM, et al. Levoglucosan indicates high levels of biomass burning aerosols over oceans from the Arctic to Antarctic. Sci Rep 2013; 3: 3119

Barn P, Larson T, Noullett M, et al. Infiltration of forest fire and residential wood smoke: an evaluation of air cleaner effectiveness. J Expo Sci Environ Epidemiol 2008; 18: 503-511.

Noullett M, Jackson PL, Brauer M. Estimation and characterization of children's ambient generated exposure to PM2.5 using sulphate and elemental carbon as tracers. Atmos Environ 2010; 44: 4629-4637.

Hoek G, Kos G, Harrison R, et al. Indoor-outdoor relationships of particle number and mass in four European cities. Atmos Environ 2008; 42: 156-169.

Nasir ZA, Colbeck I. Particulate pollution in different housing types in a UK suburban location. Sci Total Environ 2013; 445: 165-176.

Molnar P, Gustafson P, Johannesson S, et al. Domestic wood burning and PM2.5 trace elements: personal exposures, indoor and outdoor levels. Atmos Environ 2005; 39: 2643-2653.

Gustafson P, Barregard L, Strandberg B, et al. The impact of domestic wood burning on personal, indoor and outdoor levels of 1,3-butadiene, benzene, formaldehyde and acetaldehyde. J Environ Monit 2007; 9: 23-32.

Gustafson P, Ostman C, Sallsten G. Indoor levels of polycyclic aromatic hydrocarbons in homes with or without wood burning for heating. Environ Sci Technol 2008; 42: 5074-5080. Detroit and Seattle. Environ Health Perspect 2011; 119: 461-466.

Vedal S, Brauer M, White R, et al. Air pollution and daily mortality in a city with low levels of pollution. Environ Health Perspect 2003; 111: 45-51.

Browning KG, Koenig JQ, Checkoway H, et al. A questionnaire study of respiratory health in areas of high and low ambient wood smoke pollution. Pediatr Asthma Allergy Immunol 1990; 4: 183-191.

Slaughter JC, Lumley T, Sheppard L, et al. Effects of ambient air pollution on symptom severity and medication use in children with asthma. Ann Allergy Asthma Immunol 2003; 91: 346-353.

Trenga CA, Sullivan JH, Schildcrout JS, et al. Effect of particulate air, pollution on lung function in adult and pediatric subjects in a Seattle panel study. Chest 2006; 129: 1614-1622.

Norris G, YoungPong SN, Koenig JQ, et al. An association between fine particles and asthma emergency department visits for children in Seattle. Environ Health Perspect 1999; 107: 489-493.

Sheppard L, Levy D, Norris G, et al. Effects of ambient air pollution on nonelderly asthma hospital admissions in Seattle, Washington, 1987-1994. Epidemiology 1999; 10: 23-30.

Levy D, Sheppard L, Checkoway $\mathrm{H}$, et al. A case-crossover analysis of particulate matter air pollution and out-of-hospital primary cardiac arrest. Epidemiology 2001; 12: 193-199.

Sullivan J, Sheppard L, Schreuder A, et al. Relation between short-term fine-particulate matter exposure and onset of myocardial infarction. Epidemiology 2005; 16: 41-48.

Sullivan JH, Schreuder AB, Trenga CA, et al. Association between short term exposure to fine particulate matter and heart rate variability in older subjects with and without heart disease. Thorax 2005; 60: 462-466.

Sullivan JH, Hubbard R, Liu SLJ, et al. A community study of the effect of particulate matter on blood measures of inflammation and thrombosis in an elderly population. Environ Health 2007; 6: 3.

Larson T, Su J, Baribeau AM, et al. A spatial model of urban winter woodsmoke concentrations. Environ Sci Technol 2007; 41: 2429-2436.

Gehring U, Tamburic L, Sbihi H, et al. Impact of noise and air pollution on pregnancy outcomes. Epidemiology 2014; 25: 351-358

Karr CJ, Demers PA, Koehoorn MW, et al. Influence of ambient air pollutant sources on clinical encounters for infant bronchiolitis. Am J Respir Crit Care Med 2009; 180: 995-1001.

MacIntyre EA, Karr CJ, Koehoorn M, et al. Residential air pollution and otitis media during the first two years of life. Epidemiology 2011; 22: 81-89.

Gan WQ, FitzGerald JM, Carlsten C, et al. Associations of ambient air pollution with chronic obstructive pulmonary disease hospitalization and mortality. Am J Respir Crit Care Med 2013; 187: 721-727.

Clark NA, Demers PA, Karr CJ, et al. Effect of early life exposure to air pollution on development of childhood asthma. Environ Health Perspect 2010; 118: 284-290.

Wilhelm M, Ghosh JK, Su J, et al. Traffic-related air toxics and preterm birth: a population-based case-control study in Los Angeles County, California. Environ Health 2011; 10: 89.

Wilhelm M, Ghosh JK, Su J, et al. Traffic-related air toxics and term low birth weight in Los Angeles County, California. Environ Health Perspect 2012; 120: 132-138.

Andersen ZJ, Wahlin P, Raaschou-Nielsen O, et al. Ambient particle source apportionment and daily hospital admissions among children and elderly in Copenhagen. J Expo Sci Environ Epidemiol 2007; 17: 625-636.

McGowan JA, Hider PN, Chacko E, et al. Particulate air pollution and hospital admissions in Christchurch, New Zealand. Aust N Z J Public Health 2002; 26: 23-29.

Sanhueza PA, Torreblanca MA, Diaz-Robles LA, et al. Particulate air pollution and health effects for cardiovascular and respiratory causes in Temuco, Chile: a wood-smoke-polluted urban area. J Air Waste Manag Assoc 2009; 59: 1481-1488.

2 Johnston FH, Hanigan IC, Henderson SB, et al. Evaluation of interventions to reduce air pollution from biomass smoke on mortality in Launceston, Australia: retrospective analysis of daily mortality, 1994-2007. BMJ 2013; 346: e8446.

Jeong CH, Evans GJ, Dann T, et al. Influence of biomass burning on wintertime fine particulate matter: source contribution at a valley site in rural British Columbia. Atmos Environ 2008; 42: 3684-3699.

Missoula County. History of Missoula's Air Quality Program. http://www.co.missoula.mt.us/airquality/ MissoulasAir/aqhistory.htm Date last updated: 1999.

Noonan CW, Ward TJ, Navidi W, et al. A rural community intervention targeting biomass combustion sources: effects on air quality and reporting of children's respiratory outcomes. Occup Environ Med 2012; 69: 354-360.

Ward TJ, Palmer CP, Noonan CW. Fine particulate matter source apportionment following a large woodstove changeout program in Libby, Montana. J Air Waste Manag Assoc 2010; 60: 688-693.

Allen RW, Carlsten C, Karlen B, et al. An air filter intervention study of endothelial function among healthy adults in a woodsmoke-impacted community. Am J Respir Crit Care Med 2011; 183: 1222-1230. 
Kajbafzadeh M, Brauer M, Karlen B, et al. The impacts of traffic-related and woodsmoke particulate matter on measures of cardiovascular health: a HEPA filter intervention study. Occup Environ Med 2015; 72: 394-400.

Henderson SB, Johnston FH. Measures of forest fire smoke exposure and their associations with respiratory health outcomes. Curr Opin Allergy Clin Immunol 2012; 12: 221-227.

Youssouf H, Liousse C, Roblou L, et al. Non-accidental health impacts of wildfire smoke. Int J Environ Res Public Health 2014; 11: 11772-11804.

Morgan G, Sheppeard V, Khalaj B, et al. Effects of bushfire smoke on daily mortality and hospital admissions in Sydney, Australia. Epidemiology 2010; 21: 47-55.

Henderson SB, Brauer M, Macnab YC, et al. Three measures of forest fire smoke exposure and their associations with respiratory and cardiovascular health outcomes in a population-based cohort. Environ Health Perspect 2011; 119: 1266-1271.

Rappold AG, Stone SL, Cascio WE, et al. Peat bog wildfire smoke exposure in rural North Carolina is associated with cardiopulmonary emergency department visits assessed through syndromic surveillance. Environ Health Perspect 2011; 119: 1415-1420.

Straney L, Finn J, Dennekamp M, et al. Evaluating the impact of air pollution on the incidence of out-of-hospital cardiac arrest in the Perth Metropolitan Region: 2000-2010. J Epidemiol Community Health 2014; 68: 6-12.

Dennekamp M, Straney LD, Erbas B, et al. Forest fire smoke exposures and out-of-hospital cardiac arrests in Melbourne, Australia: a case-crossover study. Environ Health Perspect 2015 [In press DOI: 10.1289/ehp.1408436]. Haikerwal A, Akram M, Del Monaco A, et al. Impact of fine particulate matter (PM2.5) exposure during wildfires on cardiovascular health outcomes. J Am Heart Assoc 2015; 4: e001653.

Analitis A, Georgiadis I, Katsouyanni K. Forest fires are associated with elevated mortality in a dense urban setting. Occup Environ Med 2012; 69: 158-162.

Sastry N. Forest fires, air pollution, and mortality in southeast Asia. Demography 2002; 39: 1-23.

Bølling AK, Totlandsdal AI, Sallsten G, et al. Wood smoke particles from different combustion phases induce similar pro-inflammatory effects in a co-culture of monocyte and pneumocyte cell lines. Part Fibre Toxicol 2012; 9: 45.

Londahl J, Massling A, Swietlicki E, et al. Experimentally determined human respiratory tract deposition of airborne particles at a busy street. Environ Sci Technol 2009; 43: 4659-4664.

Londahl J, Pagels J, Boman C, et al. Deposition

of biomass combustion aerosol particles in the human Kristensson A, Rissler J, Londahl J, et al. Size-resolved respiratory tract deposition of sub-micrometer aerosol particles in a residential area with wintertime wood combustion. Aerosol Air Qual Res 2013; 13: 24-35.

Jalava PI, Aakko-Saksa P, Murtonen T, et al. Toxicological properties of emission particles from heavy duty engines powered by conventional and bio-based diesel fuels and compressed natural gas. Part Fibre Toxicol 2012; 9: 37.

Happo MS, Uski O, Jalava PI, et al. Pulmonary inflammation and tissue damage in the mouse lung after exposure to PM samples from biomass heating appliances of old and modern technologies. Sci Total Environ 2013; 443: 256-266.

Uski OJ, Happo MS, Jalava PI, et al. Acute systemic and lung inflammation in C57Bl/6J mice after intratracheal aspiration of particulate matter from small-scale biomass combustion appliances based on old and modern technologies. Inhal Toxicol 2012; 24: 952-965.

Bruns EA, Krapf M, Orasche J, et al. Characterization of primary and secondary wood combustion products generated under different burner loads. Atmos Chem Phys 2015; 15: 2825-2841.

Nordin EZ, Uski O, Nystrom R, et al. Influence of ozone initiated processing on the toxicity of aerosol particles from small scale wood combustion. Atmos Environ 2015; 102: 282-289.

Stockfelt L, Sallsten G, Olin AC, et al. Effects on airways of short-term exposure to two kinds of wood smoke in a chamber study of healthy humans. Inhal Toxicol 2012; 24: 47-59.

Barregard L, Sallsten G, Andersson L, et al. Experimental exposure to wood smoke: effects on airway inflammation and oxidative stress. Occup Environ Med 2008; 65: 319-324. volunteers. Occup Environ Med 2012; 69: 170-175.

Sehlstedt M, Dove R, Boman C, et al. Antioxidant airway responses following experimental exposure to wood smoke in man. Part Fibre Toxicol 2010; 7: 21.

Forchhammer L, Loft S, Roursgaard M, et al. Expression of adhesion molecules, monocyte interactions and oxidative stress in human endothelial cells exposed to wood smoke and diesel exhaust particulate matter. Toxicol Lett 2012; 209: 121-128.

Riddervold IS, Bonlokke JH, Molhave L, et al. Wood smoke in a controlled exposure experiment with human volunteers. Inhal Toxicol 2011; 23: 277-288

Barregard L, Sallsten G, Gustafson P, et al. Experimental exposure to wood-smoke particles in healthy humans: effects on markers of inflammation, coagulation, and lipid peroxidation. Inhal Toxicol 2006; 18: 845-853. heart rate variability in humans. Part Fibre Toxicol 2013; 10: 20

Tan WC, Qiu D, Liam BL, et al. The human bone marrow response to acute air pollution caused by forest fires. Am J Respir Crit Care Med 2000; 161: 1213-1217.

Swiston JR, Davidson W, Attridge S, et al. Wood smoke exposure induces a pulmonary and systemic inflammatory response in firefighters. Eur Respir J 2008; 32: 129-138.

Seagrave J, McDonald JD, Reed MD, et al. Responses to subchronic inhalation of low concentrations of diesel exhaust and hardwood smoke measured in rat bronchoalveolar lavage fluid. Inhal Toxicol 2005; 17: 657-670.

Barrett EG, Henson RD, Seilkop SK, et al. Effects of hardwood smoke exposure on allergic airway inflammation in mice. Inhal Toxicol 2006; 18: 33-43.

Burchiel SW, Lauer FT, Dunaway SL, et al. Hardwood smoke alters murine splenic T cell responses to mitogens following a 6-month whole body inhalation exposure. Toxicol Appl Pharmacol 2005; 202: 229-236.

Reed MD, Campen MJ, Gigliotti AP, et al. Health effects of subchronic exposure to environmental levels of hardwood smoke. Inhal Toxicol 2006; 18: 523-539.

Tesfaigzi Y, McDonald JD, Reed MD, et al. Low-level subchronic exposure to wood smoke exacerbates inflammatory responses in allergic rats. Toxicol Sci 2005; 88: 505-513. 
113 Samuelsen M, Nygaard UC, Lovik M. Allergy adjuvant effect of particles from wood smoke and road traffic. Toxicology 2008; 246: 124-131.

114 Migliaccio CT, Kobos E, King QO, et al. Adverse effects of wood smoke PM2.5 exposure on macrophage functions. Inhal Toxicol 2013; 25: 67-76.

115 Rylance J, Fullerton DG, Scriven J, et al. Household air pollution causes dose-dependent inflammation and altered phagocytosis in human macrophages. Am J Respir Cell Mol Biol 2015; 52: 584-593.

116 Tapanainen M, Jalava PI, Maki-Paakkanen J, et al. Efficiency of log wood combustion affects the toxicological and chemical properties of emission particles. Inhal Toxicol 2012; 24: 343-355.

117 Torvela T, Uski O, Karhunen T, et al. Reference particles for toxicological studies of wood combustion: formation, characteristics, and toxicity compared to those of real wood combustion particulate mass. Chem Res Toxicol 2014; 27: 1516-1527.

118 Danielsen PH, Loft S, Kocbach A, et al. Oxidative damage to DNA and repair induced by Norwegian wood smoke particles in human A549 and THP-1 cell lines. Mutat Res 2009; 674: 116-122.

119 Kocbach A, Herseth JI, Lag M, et al. Particles from wood smoke and traffic induce differential pro-inflammatory response patterns in co-cultures. Toxicol Appl Pharmacol 2008; 232: 317-326.

120 Kocbach A, Namork E, Schwarze PE. Pro-inflammatory potential of wood smoke and traffic-derived particles in a monocytic cell line. Toxicology 2008; 247: 123-132.

121 Moller P, Loft S. Oxidative damage to DNA and lipids as biomarkers of exposure to air pollution. Environ Health Perspect 2010; 118: 1126-1136.

122 Sevastyanova O, Binkova B, Topinka J, et al. In vitro genotoxicity of PAH mixtures and organic extract from urban air particles part II: human cell lines. Mutat Res 2007; 620: 123-134.

123 Riddervold IS, Bonlokke JH, Olin AC, et al. Effects of wood smoke particles from wood-burning stoves on the respiratory health of atopic humans. Part Fibre Toxicol 2012; 9: 12.

124 Wagner F, Amann M, Bertok I, et al. NEC Scenario Analysis Report Nr. 7. Baseline emission projections and further cost-effective reductions of air pollution impacts in Europe - a 2010 perspective. Laxenburg, International Institute for Applied Systems Analysis, 2010.

125 European Comission. EC (2013) Commission staff working document: Impact assessment SWD(2013)531. Brussels, European Commission, 2013.

126 European Environment Agency. Air quality in Europe - 2014 report. Luxembourg, European Environment Agency, 2014.

127 Chafe Z, Brauer M, Heroux ME, et al. Residential heating with wood and coal: health impacts and policy options in Europe and North America. Copenhagen, WHO Regional Office for Europe, 2015.

Brunekreef B, Künzli N, Pekkanen J, et al. Clean air in Europe: beyond the horizon? Eur Respir J 2015; 45: 7-10. 